OPEN ACCESS

Edited by:

Xin Zhou,

Nanjing Forestry University, China

Reviewed by:

Xiaoju Wang,

Åbo Akademi University, Finland

Wen Zeng,

Chongqing University, China

*Correspondence:

Nong Zhou

erhaizn@126.com

Ming-Guo Ma

mg_ma@bjfu.edu.cn

Sun-Eun Cho

oregonin@kangwon.ac.kr

Chuanling Si

sichli@tust.edu.cn

Specialty section:

This article was submitted to

Bioprocess Engineering,

a section of the journal

Frontiers in Bioengineering and

Biotechnology

Received: 24 May 2021

Accepted: 22 June 2021

Published: 22 July 2021

Citation:

Zhou N, Xu L, Park S-M, Ma M-G

Choi S-E and Si C (2021) Genetic

Diversity, Chemical Components,

and Property of Biomass Paris

polyphylla var. yunnanensis.

Front. Bioeng. Biotechnol. 9:713860.

doi: 10.3389/fbioe.2021.713860

\section{Genetic Diversity, Chemical Components, and Property of Biomass Paris polyphylla var. yunnanensis}

\author{
Nong Zhou ${ }^{1 *}$, Lingfeng $\mathrm{Xu}^{1}$, Sun-Min Park², Ming-Guo Ma ${ }^{1,3 *}$, Sun-Eun $\mathrm{Choi}^{2 *}$ and \\ Chuanling $\mathrm{Si}^{4 *}$
}

\begin{abstract}
${ }^{1}$ Chongqing Engineering Laboratory of Green Planting and Deep Processing of Famous-Region Drug in the Three Gorges Reservoir Region, College of Biology and Food Engineering, Chongqing Three Gorges University, Chongqing, China, ${ }^{2}$ Department of Forest Biomaterials Engineering, College of Forest and Environmental Sciences, Kangwon National University, Chuncheon, South Korea, ${ }^{3}$ Beijing Key Laboratory of Lignocellulosic Chemistry, Research Center of Biomass Clean Utilization, Engineering Research Center of Forestry Biomass Materials and Bioenergy, College of Materials Science and Technology, Beijing Forestry University, Beijing, China, ${ }^{4}$ Tianjin Key Laboratory of Pulp and Paper, Tianjin University of Science and Technology, Tianjin, China
\end{abstract}

Paris polyphylla var. yunnanensis is a kind of biomass resource, which has important medicinal and economical values with a huge market. This review article aims to summarize the recent development of biomass P. polyphylla var. yunnanensis. The genetic diversity and chemical components of biomass P. polyphylla var. yunnanensis were reviewed based on the literature. Both the genetic diversity and genetic structure of biomass $P$. polyphylla var. yunnanensis were compared by using molecular marker technologies. All the extraction processes, harvest time, and drying methods on the chemical components were summarized in detail. The differences of arbuscular mycorrhizal fungi on the infection rate, diosgenin content, microorganisms, enzyme activities, rhizospheric environment, and endogenous hormones were discussed. This review article is beneficial for the applications of biomass $P$. polyphylla var. yunnanensis as a biomass resource in the biomedical field. Keywords: Paris polyphylla var. yunnanensis, development, genetic diversity, molecular markers, chemical
components

\section{INTRODUCTION}

Paris polyphylla is a perennial herb and has various properties including clearing away heat, detoxification, detumescence, pain relief, and calming convulsion, which is widely used in the furuncle, carbuncle, sore throat, snakebite, tumbling pain, and convulsion fields. It was reported that P. polyphylla is mainly distributed in the tropics of Europe and Asia (Liang and Victor, 2000). In China, it is mainly distributed in Sichuan Province, Guizhou Province, Yunnan Province, Guangxi Province, Guangdong Province, Jiangxi Province, Fujian Province, etc. P. polyphylla var. 
yunnanensis is located in Yunnan Province, Guizhou Province, Sichuan Province, and Chongqing city (Liu et al., 2015). P. polyphylla var. yunnanensis mainly contains chemical constituents of steroidal saponins, $\beta$-ecdysone, polysaccharide, flavone glycoside, and amino acids, which have important medicinal and economical values. Research shows that $P$. polyphylla var. yunnanensis has antibacterial and antitussive effects. In addition, the saponins of $P$. polyphylla var. yunnanensis have anticancer, analgesic, and sedative properties. The Chinese Pharmacopoeia (2015 edition) collected $P$. polyphylla var. yunnanensis as an important medicinal plant in 81 kinds of Chinese patent medicines, such as "Yunnan Baiyao," "Gongxuening Capsule," and so on (National Pharmacopoeia Commission, 2015).

With the rapid development of the Chinese traditional medicine industry, the demand for P. polyphylla var. yunnanensis as a raw material increased greatly. The wild $P$. polyphylla var. yunnanensis does not meet the requirements. More importantly, it takes 8-10 years from planting to harvesting and utilization of P. polyphylla var. yunnanensis. The price of P. polyphylla var. yunnanensis increased dramatically, resulting in the scarcity of the species. It was reported that more than 1,000 tons of P. polyphylla var. yunnanensis was utilized every year and about $80 \%$ of the wild $P$. polyphylla var. yunnanensis distributed in China has been utilized. Currently, wild resources cannot meet the demand of the market. The scarcity of $P$. polyphylla var. yunnanensi resources may become a bottleneck, restricting the sustainable development of the related pharmaceutical industry. Therefore, the development of artificial planting is an important choice to solve the shortage of $P$. polyphylla var. yunnanensis resources (Cunningham et al., 2018). In addition, the current research is about the total saponins of $P$. polyphylla var. yunnanensis. The basic research of P. polyphylla var. yunnanensis needs to be further explored in detail. It is necessary to separate and purify the active monomer components and study their activity to develop more valuable new drugs (Chen et al., 2016; Yang et al., 2019, 2021; Chen et al., 2020a; Ma et al., 2020; Wang et al., 2021). In the previous article, Negi et al. (2014) reviewed the developmental prospects of chemistry and biology of P. polyphylla. After that, Cunningham et al. (2018) assessed the scale of $P$. polyphylla trade, reviewing evidence about the impacts of wild harvest on $P$. polyphylla populations and the role of cultivation as an alternative to wild harvest. More recently, Pei et al. (2020) reviewed medicinal records of ethnic minorities for $P$. polyphylla in China and indicated the applications of authentic evaluation techniques of ethnobotanical medicinal plant of genus P. polyphylla.

The purpose of this review article is to introduce the development and problem of P. polyphylla var. yunnanensis based on previous research. The article analyzed the genetic diversity and structure of wild populations and cultivated populations of $P$. polyphylla var. yunnanensis and compared the different molecular markers methods. Then, the effects of fungi on the properties of $P$. polyphylla var. yunnanensis were also reviewed. Finally, the problems and suggestions were given on the P. polyphylla var. yunnanensis based on our present knowledge. It was expected that this review article favored the applications of $P$. polyphylla var. yunnanensis in the natural medicine field.
More research should be focused on the artificial planting, genetic diversity, structure, properties, and applications of $P$. polyphylla var. yunnanensis.

\section{THE POPULATION GENETICS OF Paris polyphylla var. yunnanensis}

In the literature, $P$. polyphylla var. yunnanensis was first recorded in Shennong's Herbal Classic of Materia Medica under the name of "Zaoxiu." After that, it was recorded in famous books, such as "Supplementary Records of Famous Physicians," "Tang Materia Medica," "Rihuazi Materia Medica," and so on, containing the contents of the morphology, growth environment, and properties of P. polyphylla var. yunnanensis.

There are many reports on the genetic diversity and genetic structure of $P$. polyphylla and its related species inside and outside the region (He et al., 2007; Yang et al., 2015; Zhao X.P. et al., 2020). A random amplified polymorphic DNA (RAPD) molecular marker was developed by Wiliam and Welsh in 1990 to detect DNA polymorphism by PCR. This research indicated the important applications of $P$. polyphylla. For example, Zhang et al. (2004) reported the genetic diversity of $P$. polyphylla var. yunnanensis from Yunnan, Guangxi, and Vietnam using RAPD molecular marker.

Simple sequence repeats (SSRs) molecular marker is a DNA molecular marker technology based on PCR. In $\mathrm{He}$ et al. (2007), the genetic diversity and genetic structure of cultivated and wild $P$. polyphylla were reported based on inter-simple sequence repeat (ISSR) molecular marker. It showed that the genetic diversity (polymorphism) of the cultivated population was higher than that of the wild population ( 0.153 vs. 0.151$)$. The result indicated that the artificial planting was a realistic strategy for solving the shortage of $P$. polyphylla var. yunnanensis resource. In addition, the genetic diversity (polymorphism) of 62 individuals of $P$. polyphylla var. yunnanensis from Yunnan Province was explored based on SSRs molecular marker (Song et al., 2015). They developed 10 pairs of primers to provide a primer basis for the SSR marker of P. polyphylla var. yunnanensis. In Chen et al. (2017), the genetic diversity of 115 samples from 5 populations in Yunnan was analyzed based on simple sequence repeats (SSR) molecular marker. The results showed that the expected heterozygosity was 0.774 at the species level and 0.655 at the population level, respectively, indicating the high genetic diversity of $P$. polyphylla var. yunnanensis.

Amplified fragment length polymorphism (AFLP) molecular marker was a method for detecting DNA polymorphism developed by Vos et al. (1995) in Netherlands in 1995, which is a combination of RFLP and PCR. Li et al. (2018) used AFLP molecular marker to analyze the genetic diversity of P. polyphylla var. yunnanensis from 15 populations in Yunnan Province. Research group investigated the genetic diversity (polymorphism) and genetic structure of $P$. polyphylla var. yunnanensis, 15 wild populations, and 17 cultivated populations, based on AFLP molecular marker and cpDNA fragments (Huang Y. et al., 2019; Hu et al., 2014, 2016). According to the analysis of molecular variance (AMOVA), only 1.35\% of genetic variation existed between wild and cultivated populations, 
indicating that there was no obvious genetic differentiation between wild and cultivated populations, due to the relatively short history of the domestication of cultivated populations. The chloroplast gene, cpDNA fragment (trnL TRNF), was used to analyze the phylogeography of wild $P$. polyphylla var. yunnanensis (Zhao J.J. et al., 2020). The genetic structure of 17 cultivated populations showed mixed provenances in the cultivation base, leading to unstable quality. The cpDNA fragment (trnL TRNF) is a rapid, economic, and effective strategy to analyze the phylogeography of $P$. polyphylla var. yunnanensis.

A variety of molecular marker technologies have been developed rapidly, which were widely used in plant genetic research (Chen et al., 2020b; Liu H. et al., 2021a,b; Liu K. et al., 2021; Liu et al., 2021). Molecular marker technologies is used in the applications of the breeding and production of animals and plants, which mainly focus on gene mapping, assisted breeding, disease treatment, etc. The development of molecular marker technology is a hot topic in the field of molecular biology (An et al., 2019; Du et al., 2019, 2021; Li et al., 2019; Xu J. et al., 2021). With the rapid development of molecular biology theory, molecular marker technology will be developed with fast analysis speed, low cost, and more information (Ma et al., 2021a,b; Xu et al., 2020; Xu R. et al., 2021).

Yang et al. (2016) reported the bacterial strain, py1294(T), isolated from a root of $P$. polyphylla var. yunnanensis by using a polyphasic approach to clarify its taxonomic position. They indicated that the strain py1294(T) formed a well-supported clade with Oceanobacillus damuensis PT-20(T) (97.9\% sequence similarity) within the genus Oceanobacillus. It obtained the DNA-DNA relatedness value of $29.7 \%$ between strain py129 (T) and O. damuensis PT-20(T). Jia et al. (2016) isolated two actinobacteria, designated strains NEAU-JM1(T) and NEAUCL2(T), from volcanic sediment and the rhizosphere soil of P. polyphylla. They established the taxonomic positions of these strains and concluded these two species of the genus Catellatospora.

As early as Xuan et al. (2010) isolated fungal endophyte from P. polyphylla Smith var. yunnanensis and identified its antibacterial ability. Authors obtained 18 fungal endophytes, parasitizing the famous Chinese medicinal plant $P$. polyphylla Smith var. yunnanensis, and evaluating the effect of endophytes on the growth of human pathogenic microbes in vitro using disk diffusion assay. Then, Zhou et al. (2012) investigated the effects of fungal elicitors on the secondary metabolite steroidal saponin in P. polyphylla var. yunnanensis. There was selectivity between arbuscular mycorrhizal fungal and $P$. polyphylla var. yunnanensis, and Glomus intraradice was the most appropriate strain for inoculation of P. polyphylla var. yunnanensis. Recently, Wang Y. et al. (2020) investigated the effects of altitude on the community composition of endophytic fungal communities and the differentiation of endophytic microorganisms among different niches in $P$. polyphylla. The author also indicated that the structural variability in the rhizosphere fungal community was significantly lower than that in the endophytic communities, confirming the presence of niche differentiation among members of the endophytic microbial community.

There is a connection between the genetic and the fungal sections; however, there are few reports on this topic. Therefore, more rapid attention should be paid on the connection between the genetic and the fungal sections of $P$. polyphylla var. yunnanensis in the near future.

\section{THE CHEMICAL COMPONENTS OF Paris polyphylla var. yunnanensis}

The polysaccharides have a variety of pharmacological and biological functions, such as antioxidant, antitumor, antiviral, immune regulation, and anti-inflammatory (Si et al., 2008a,b, 2009, 2013; Dai et al., 2020a,b). P. polyphylla var. yunnanensis, as an important plant polysaccharide, has attracted more attention in recent years (Jing et al., 2017; Shen et al., 2018). P. polyphylla has been reported to contain a variety of chemical components including daucosterol, polyphyllin D, beta-ecdysterone, Paris saponins I, II, V, VI, VII, H, dioscin, oligosaccharides, heptasaccharide, octasaccharide, trigofoenoside A, protogracillin, Paris yunnanosides G-J, padelaoside B, and pinnatasterone, which have biological properties, such as anticancerous, antitumor, cytotoxic, anthelmintic, antimicrobial, antiangiogenic, immunostimulating, contractile, and hemostatic (Negi et al., 2014; Liu et al., 2020a,b; Wang H. et al., 2020). There are many reports on the extraction and applications of polysaccharides, P. polyphylla var. yunnanensis (Huang et al., 2007; Chan et al., 2011; Wu et al., 2012; Qin et al., 2016).

As early as Zhou et al. (2003) investigated the heptasaccharide and octasaccharide isolated from $P$. polyphylla var. yunnanensis and their plant growth-regulatory activity. In Shen et al. (2014) reported the optimization of the extraction process and antioxidant activity of polysaccharides from the leaves of P. polyphylla. The monosaccharide components of P. polyphylla var. yunnanensis were obtained using the hydrolysis method at $110^{\circ} \mathrm{C}$ temperature for $6 \mathrm{~h}$ in $2 \mathrm{~mol} \cdot \mathrm{L}^{-1}$ trifluoroacetic acid (Wang et al., 2019). The recoveries of five monosaccharide components were 92.38-99.98\%. The polysaccharides of $P$. polyphylla var. yunnanensis were mainly composed of glucose, mannose, galactose, rhamnose, and arabinose, whose molar ratio in wild species was 219.22:28.23:1.83:1.44:1.00.

Research group extracted the polysaccharide of $P$. polyphylla var. yunnanensis through three different extraction processes, such as reflux extraction, hot water extraction, and ultrasonicassisted extraction (Zhou et al., 2014). It was found that the P. polyphylla var. yunnanensis extracted by ultrasonic-assisted extraction method had the highest polysaccharide content of $24.32 \mathrm{mg} \mathrm{g}^{-1}$. We also found the change content of diosgenin significantly in P. polyphylla var. yunnanensis at different harvest times (Zhou et al., 2010). It has been observed that the content was increased gradually from April to June, the highest content was from May to June, and the content was decreased sharply from June to July. The influence of the drying method on the diosgenin of $P$. polyphylla var. yunnanensis was also explored (Zhou et al., 2015b). It was found that the color changed from white to light brown and powdery using the drying at 35C, natural shade drying, and sun-drying had good color, while the color changed from brown to dark brown and horny by those of other drying methods. Different drying methods had different effects on the diosgenin of P. polyphylla var. yunnanensis. 
As early as Lee et al. (2005) investigated the effects of polyphyllin D, a steroidal saponin in P. polyphylla, on growth inhibition of human breast cancer cells and in xenograft. Then, Yan et al. (2009) confirmed anticancer activity of steroid saponins of P. polyphylla var. yunnanensis by both in vitro and in vivo. After that, Wang et al. (2010) investigated the anthelmintic activity of crude extracts and pure compounds from the rhizomes of $P$. polyphylla. In addition, steroidal saponins from the rhizome of $P$. polyphylla and their cytotoxic activities were also researched using two new furostanol saponins and one new spirostanol saponin isolated from the rhizome of $P$. polyphylla var. yunnanensis, together with 18 known steroidal saponins (Zhao et al., 2009; Hu et al., 2017, 2018). There was a report on the steroidal saponins with antimicrobial activity from stems and leaves of P. polyphylla var. yunnanensis (Qin et al., 2012). The effects of nine different drying methods on the content of total saponins in rhizomes of $P$. polyphylla var. yunnanensis and the differences in antioxidant activity were also studied (Zhang et al., 2016). The total saponin content of different drying methods was significantly different in rhizomes of P. polyphylla var. yunnanensis.

Four saponins were investigated in $P$. polyphylla var. yunnanensis with different growth years (Zhang et al., 2011). It was found that the content of saponins of $P$. polyphylla var. yunnanensis in 3-year-old herbs was lower than those in 4-year-old and 5-year-old herbs. The contents of nine steroidal saponins were reported in rhizomes and fibrous roots of P. polyphylla var. yunnanensis ( $\mathrm{Gu}$ et al., 2020a). The quite different content of steroidal saponins in 32 samples of P. polyphylla var. yunnanensis was obtained from different areas. Most of them could detect nine kinds of steroidal saponins in rhizomes. The $P$. polyphylla var. yunnanensis had rich contents of saponins I and II and relatively low contents of saponins VI and dioscin. The effects of ultrasonic extraction and hot water extraction on the extraction of nucleoside from $P$. polyphylla var. yunnanensis were analyzed using rhizome as experimental materials and the total extraction amount of six nucleosides (cytidine, uridine, guanosine, thymidine, adenosine, and deoxyadenosine) as the index was analyzed, in which the extraction amount was determined by high-performance liquid chromatography (HPLC) (Yang et al., 2017). The results showed that the total extraction amount of six nucleosides from rhizomes of P. polyphylla var. yunnanensis by ultrasonic extraction was higher than that of the hot water extraction method. The total extraction amount of cytidine, uridine, guanosine, thymidine, adenosine, and deoxyadenosine from rhizomes of $P$. polyphylla var. yunnanensis was $1.422 \mathrm{mg} \mathrm{g}^{-1}$, which was higher than the theoretical value of $1.343 \mathrm{mg} \mathrm{g}^{-1}$.

The amino acids of $P$. polyphylla var. yunnanensis were investigated in 27 samples of $P$. polyphylla var. yunnanensis collected from Yunnan Province, Guizhou Province, and Sichuan Province (Gu et al., 2020b). The good linear relationship of 15 amino acids in fibrous roots of $P$. polyphylla var. yunnanensis was observed, among which the highest contents of aspartic acid and glutamic acid were found in all producing areas. The transplanting $P$. polyphylla var. yunnanensis had high contents of amino acids in fibrous roots compared with that of the wild P. polyphylla var. yunnanensis. The contents of inorganic elements were investigated in both Yunnan Province and Guizhou Province (Yang et al., 2018). The good linear relationship of 14 inorganic elements and the average recovery rate of $90.81-109.73 \%$ was found. There are obvious differences among the mass fraction and composition structure ratio of 14 inorganic elements in P. polyphylla var. yunnanensis medicinal material from different places.

Based on the previous reports, it was found that the extraction processes, harvest time, drying methods, growth years, extraction methods, and other factors had an impact on the chemical components of $P$. polyphylla var. yunnanensis. More research should be developed on the chemical components of $P$. polyphylla var. yunnanensis in detail.

\section{THE EFFECTS OF FUNGI ON THE CONTENT AND PROPERTIES of Paris Polyphylla var. Yunnanensis}

In the literature, the fungi were reported to play an important role in the contents and properties of $P$. polyphylla var. yunnanensis (Li et al., 2008; Huang et al., 2009; Liu et al., 2017). The effects of 28 arbuscular mycorrhizal fungi on the infection rate and diosgenin content of $P$. polyphylla var. yunnanensis were explored in sterilized soil (Wang et al., 2018). The results indicated that there was a good symbiotic relationship between $P$. polyphylla var. yunnanensis and arbuscular mycorrhizal fungi, and the significant increase in infection rate. More importantly, it was found that there was no significant difference between the diosgenin contents of P. polyphylla var. yunnanensis and the control group; however, it was observed a significant increase in diosgenin content of $41.40 \mathrm{mg} \mathrm{g}^{-1}$ after treatment with Svi fungi. The effects of inoculation periods on growth and steroidal saponin content of P. polyphylla var. yunnanensis seedlings infected by arbuscular mycorrhizal fungi were investigated (Huang Y.P. et al., 2019). The strong infection rate of arbuscular mycorrhizal fungi in different inoculation periods, the increased protective enzyme activity, photosynthetic pigment, and soluble sugar content were found. The inoculation time had a certain influence on the growth and development of $P$. polyphylla var. yunnanensis seedlings infected by arbuscular mycorrhizal fungi and the saponins content of $P$. polyphylla var. yunnanensis. The effects of arbuscular mycorrhizal fungi on the number of microorganisms and enzyme activities in rhizosphere soil of $P$. polyphylla var. yunnanensis were investigated (Ou et al., 2016). One can observe that there was a certain degree of mutual selectivity between P. polyphylla var. yunnanensis and arbuscular mycorrhizal fungi. After the induction of arbuscular mycorrhizal fungi, the different arbuscular mycorrhizal fungus had different effects on the number of microorganisms, microbial biomass carbon, and soil enzyme activities in rhizosphere soil of $P$. polyphylla var. yunnanensis.

Research group (Zhou et al., 2020) studied the effect of arbuscular mycorrhizal fungi treatments of different combinations on the rhizospheric environment of $P$. polyphylla var. yunnanensis. The inoculation of arbuscular mycorrhizal fungi could regulate the spore densities and the colonizations 
of $P$. polyphylla var. yunnanensis rhizosphere arbuscular mycorrhizal to improve the root activity. Effects of arbuscular mycorrhizal fungi on endogenous hormones in $P$. polyphylla var. yunnanensis were reported (Zhou et al., 2017). It was found that the inoculation of exogenous arbuscular mycorrhizal fungi could improve the mycorrhizal infection rate and seedling rate of $P$. polyphylla var. yunnanensis seedlings. The arbuscular mycorrhizal fungi had different rules on the changes in the rhizome and fibrous root of $P$. polyphylla var. yunnanensis seedlings. Fifty strains of endophytic fungus were isolated from phloem, xylem, and seed of rhizome of $P$. polyphylla var. yunnanensis collected from Yunnan Province (Zhou et al., 2004). The most endophytic fungi was isolated from the phloem of the rhizome. In addition, steroids in the fermentation cultures of 32 strains of endophytic fungus was detected, and the yield of steroids in the fermentation cultures of five strains of endophytic fungus exceeded $50 \mathrm{mg} \mathrm{L}^{-1}$.

Zhang et al. (2019) reported the arbuscular mycorrhizal fungi suitable for the growth and development of P. polyphylla var. yunnanensis seedlings screened with mycorrhizal viability, rhizome biomass, and active components as indexes. It was found that the 28 arbuscular mycorrhizal fungi inoculated with P. polyphylla var. yunnanensis formed a symbiotic system, and could improve the mycorrhizal viability of $P$. polyphylla var. yunnanensis seedlings. Research group found that exogenous arbuscular mycorrhizal fungi could regulate the spore density, infection rate, and infection intensity of arbuscular mycorrhizal fungi in roots of $P$. polyphylla var. yunnanensis, and enhance the activities of succinate dehydrogenase and alkaline phosphatase of hyphae in roots of P. polyphylla var. yunnanensis (Zhou et al., 2015a). After treated with arbuscular mycorrhizal fungal elicitors, the different effects of different arbuscular mycorrhizal fungus on different steroidal saponins in rhizomes of $P$. polyphylla var. yunnanensis was observed. The application of arbuscular mycorrhizal fungi could improve the medicinal quality of $P$. polyphylla var. yunnanensis.

Indeed, the mechanism at the molecular level is also needed to be further studied in detail, which is important for the applications of $P$. polyphylla var. yunnanensis. In addition, the utilization of biotechnological processes should be developed for the production of $P$. polyphylla var. yunnanensis under controlled conditions.

\section{CONCLUSION AND PERSPECTIVES}

There are many reports on the genetic diversity, genetic structure, and chemical components of P. polyphylla var. yunnanensis. The fungi also affected the contents and properties of P. polyphylla

\section{REFERENCES}

An, L., Si, C., Wang, G., Sui, W., and Tao, Z. (2019). Enhancing the solubility and antioxidant activity of high-molecular-weight lignin by moderate depolymerization via in situ ethanol/acid catalysis. Ind. Crops Prod. 128, 177185. doi: 10.1016/j.indcrop.2018.11.009

Chan, J. Y. W., Koon, J. C. M., Liu, X. Z., Detmar, M., Yu, B. A., Kong, S. K., et al. (2011). Polyphyllin D, a steroidal saponin from Paris polyphylla, inhibits endothelial cell functions in vitro and angiogenesis in Zebrafish var. yunnanensis; however, there are few review articles on the $P$. polyphylla var. yunnanensis. This review article provided the recent development about the genetic diversity and structure of P. polyphylla var. yunnanensis based on the literature. More attention should be paid to the genetic diversity and genetic structure, which favored the replacement of the wild population by the cultivated population. In addition, the differences between wild population and cultivated population should be investigated in detail, which is important for the applications of P. polyphylla var. yunnanensis. Especially, the effect of areas on the quality and chemical components of $P$. polyphylla var. yunnanensis should be explored. Furthermore, more methods should be developed on the extraction and purity of the chemical components of P. polyphylla var. yunnanensis. The mechanism between chemical components and biological activities should be discussed by more experimental results. Furthermore, the utilization of fungi on the properties of $P$. polyphylla var. yunnanensis should be developed in detail. More biomedical properties should be investigated. It is well-known that $P$. polyphylla var. yunnanensis is an important biomass resource in the natural medicine field (Liu H. et al., 2021a,b). Therefore, the mechanism between chemical components and properties should be researched in depth. We expected that this review article is beneficial to expand the applications of P. polyphylla var. yunnanensis in the biomedical field.

\section{AUTHOR CONTRIBUTIONS}

NZ, LX, and M-GM: investigation. S-MP, S-EC, and CS: supervision. NZ and M-GM: writing - original draft. M-GM, S-MP, LX, S-EC, and CS: writing - review and editing. All authors contributed to the article and approved the submitted version.

\section{FUNDING}

This research was supported by the National Natural Science Foundation of China (No. 81260622), Chongqing Science and Technology Commission (cstc2018jcyjAX026), the "Beyond Research Innovation \& Development for Good Enterprises+" Project, supported by the Ministry of Education (MOE), the Technology Development Program (S3030198) funded by the Ministry of SMEs and Startups (MSS, South Korea), and this work was also partially supported by 2020' Jeollannamdo ("Industry-University-Institute collaboration agricultural industrial complex R\&D supporting program” operated by Jeonnam Technopark) to S-EC.

embryos in vivo. J. Ethnopharmacol. 137, 64-69. doi: 10.1016/j.jep.2011 .04 .021

Chen, S., Wang, G., Sui, W., Parvez, A. M., Dai, L., and Si, C. (2020a). Novel lignin-based phenolic nanosphere supported palladium nanoparticles with highly efficient catalytic performance and good reusability. Ind. Crop Prod. 145:112164. doi: 10.1016/j.indcrop.2020.11 2164

Chen, S., Wang, G., Sui, W., Parvez, A. M., and Si, C. (2020b). Synthesis of ligninfunctionalized phenolic nanosphere supported Ag nanoparticles with excellent 
dispersion stability and catalytic performance. Green Chem. 22, 2879-2888. doi: $10.1039 / \mathrm{c} 9 \mathrm{gc} 04311 \mathrm{j}$

Chen, X., Yang, Q., Si, C. L., Wang, Z., Huo, D., Hong, Y., et al. (2016). Recovery of oligosaccharides from prehydrolysis liquors of poplar by microfiltration/ultrafiltration membranes and anion exchange resin. ACS Sustain. Chem. Eng. 4, 937-943. doi: 10.1021/acssuschemeng.5b01029

Chen, Z. S. Z., Tian, B., and Cai, C. T. (2017). Genetic diversity of Paris polyphylla var. yunnanensis based on SSR molecular markers. Chin. Herb. Med. 48, 1834-1838.

Cunningham, A. B., Brinckmann, J. A., Bi, Y. F., Pei, S. J., Schippmann, U., and Luo, P. (2018). Paris in the spring: a review of the trade, conservation and opportunities in the shift from wild harvest to cultivation of Paris polyphylla (Trilliaceae). J. Ethnopharmacol. 222, 208-216. doi: 10.1016/j.jep.2018.04.048

Dai, L., Cao, Q., Wang, K., Han, S., Si, C., Liu, D., et al. (2020a). High efficient recovery of L-lactide with lignin-based filler by thermal degradation. Ind. Crop Prod. 143:111954. doi: 10.1016/j.indcrop.2019.111954

Dai, L., Ma, M., Xu, J., Si, C., Wang, X., Liu, Z., et al. (2020b). All-lignin-based hydrogel with fast ph-stimuli responsiveness for mechanical switching and actuation. Chem. Mater. 32, 4324-4330. doi: 10.1021/acs.chemmater.0c01198

Du, H., Liu, W., Zhang, M., Si, C., Zhang, X., and Li, B. (2019). Cellulose nanocrystals and cellulose nanofibrils based hydrogels for biomedical applications. Carbohydr. Polym. 209, 130-144. doi: 10.1016/j.carbpol.2019.01. 020

Du, H., Parit, M., Liu, K., Zhang, M., Jiang, Z., Huang, T.-S., et al. (2021). Engineering cellulose nanopaper with water resistant, antibacterial, and improved barrier properties by impregnation of chitosan and the followed halogenation. Carbohydr. Polym. 270:118372. doi: 10.1016/j.carbpol.2021. 118372

Gu, W. C., Guo, D. Q., Yang, M., Huang, X. L., Li, H. L., and Zhou, N. (2020a). Determination of 9 steroidal saponins in rhizome and fibrous roots of wild and cultivated Paris polyphylla var. yunnanensis by UPLC. Trad. Chin. Drug Res. Clin. Pharmacol. 31, 838-847.

Gu, W. C., Zhao, S. X., Yang, M., Huang, X. L., Li, H. L., and Zhou, N. (2020b). Simultaneous determination of amino acids in Paris polyphylla var. yunnanensis fibril from different habitats by UPLC. Nat. Product Res. Dev. 32, 1562-1575.

He, J., Wang, H., Li, D. Z., and Chen, S. F. (2007). Genetic diversity of Paris polyphylla var. yunnanensis, a traditional Chinese medicinal herb, detected by ISSR markers. Planta Med. 73, 1316-1321. doi: 10.1055/s-2007-98 1617

Hu, L., Du, H., Liu, C., Zhang, Y., Yu, G., Zhang, X., et al. (2018). Comparative evaluation of the efficient conversion of corn husk filament and corn husk powder to valuable materials via a sustainable and clean biorefinery process. ACS. Sustain. Chem. Eng. 7, 1327-1336. doi: 10.1021/acssuschemeng.8b05017

Hu, L., Wang, K., Li, G., Zhang, R., Luo, Y., Si, C., et al. (2017). Isolation and structural elucidation of heartwood extractives of Juglans sigillata. Holzforschung 71, 785-791. doi: 10.1515/hf-2017-0036

Hu, W. C., Wang, G. C., Li, P. X., Wang, Y. N., Si, C. L., He, J., et al. (2014). Neuroprotective effects of macranthoin G from Eucommia ulmoides against hydrogen peroxide-induced apoptosis in PC12 cells via inhibiting NFkappa B activation. Chem. Biol. Interact. 224, 108-116. doi: 10.1016/j.cbi.2014.10.011

Hu, W. C., Wang, X. F., Wu, L., Shen, T., Ji, L. L., Zhao, X. H., et al. (2016). Apigenin-7-O-beta-D-glucuronide inhibits LPS-induced inflammation through the inactivation of AP-1 and MAPK signaling pathways in RAW 264.7 macrophages and protects mice against endotoxin shock. Food Funct. 7 , 1002-1013. doi: 10.1039/c5fo01212k

Huang, Y., Cui, L. J., Zhan, W. H., Dou, Y. H., Wang, Y. L., Wang, Q., et al. (2007). Separation and identification of steroidal compounds with cytotoxic activity against human gastric cancer cell lines in vitro from the rhizomes of Paris polyphylla var. chinensis. Chem. Nat. Comp. 43, 672-677. doi: 10.1007/ s10600-007-0225-8

Huang, Y., Zhou, N., Yang, M., Shen, Y. X., and Zhang, D. Q. (2019). A comparative study of the population genetics of wild and cultivated populations of Paris polyphylla var. yunnanensis based on amplified fragment length polymorphism markers. Ecol. Evol. 9, 10707-10722. doi: 10.1002/ece3.5589

Huang, Y. P., Zhang, J., Yang, M., Ding, B., Guo, D. Q., Pan, X. J., et al. (2019). Effects of different inoculation periods on seedling growth and steroidal saponin content of Paris polyphylla var. Yunnanensis. Chin. Trad. Herb. Drugs $50,4438-4448$.
Huang, Y. F., Zhao, J. L., Zhou, L. G., Wang, M. A., Wang, J. G., Li, X. L., et al. (2009). Antimicrobial compounds from the endophytic Fungus Fusarium sp Ppf4 isolated from the medicinal plant Paris polyphylla var. Yunnanensis. Nat. Product Commun. 4, 1455-1458. doi: 10.1177/1934578X0900401102

Jia, F. Y., Guo, S. Y., Shen, Y., Gao, M. Y., Liu, C. X., Zhou, S. Y., et al. (2016). Catellatospora vulcania sp nov and Catellatospora paridis sp nov., two novel actinobacteria isolated from volcanic sediment and the rhizosphere of Paris polyphylla. Antonie Van Leeuwenhoek Intern. J. Gen. Mol. Microbiol. 109, 43-50. doi: 10.1007/s10482-015-0608-y

Jing, S. S., Wang, Y., Li, X., Man, S. L., and Gao, W. Y. (2017). Chemical constituents and antitumor activity from Paris polyphylla Smith var. yunnanensis. Nat. Product Res. 31, 660-666. doi: 10.1080/14786419.2016. 1219861

Lee, M. S., Yuet-Wa, J. C., Kong, S. K., Yu, B., Eng-Choon, V. O., Nai-Ching, H. W., et al. (2005). Effects of polyphyllin D, a steroidal saponin in Paris polyphylla, in growth inhibition of human breast cancer cells and in xenograft. Cancer Biol. Ther. 4, 1248-1254. doi: 10.4161/cbt.4.11.2136

Li, J., Zhao, J. L., Xu, L. J., Zhou, L. G., Li, X. L., and Wang, J. G. (2008). Endophytic fungi from rhizomes of Paris polyphylla var. Yunnanensis. World J. Microbiol. Biotechnol. 24, 733-737. doi: 10.1007/s11274-007-9531-3

Li, Y. B., Wang, L., and He, Z. J. (2018). AFLP analysis of genetic diversity of Paris polyphylla. Botan. Res. 7, 45-53. doi: 10.12677/br.2018.71007

Li, X., Xu, R., Yang, J., Nie, S., Liu, D., Liu, Y., et al. (2019). Production of 5-hydroxymethylfurfural and levulinic acid from lignocellulosic biomass and catalytic upgradation. Ind. Crops Prod. 130, 184-197. doi: 10.1016/j.indcrop. 2018.12.082

Liang, S., and Victor, G. S. (2000). "Paris L," in Flora of China, eds Z. Y. Wu and P. H. Raven (Beijing: China Sciences Press), 88-95.

Liu, H., Xu, T., Liu, K., Zhang, M., Liu, W., Li, H., et al. (2021a). Lignin-based electrodes for energy storage application. Ind. Crops Prod. 165:113425. doi: 10.1016/j.indcrop.2021.113425

Liu, H., Du, H., Zheng, T., Liu, K., Ji, X., and Xu, T. (2021b). Cellulose based composite foams and aerogels for advanced energy storage devices. Chem. Eng. J. 426:130817. doi: 10.1016/j.cej.2021.130817

Liu, K., Du, H., Zheng, T., Liu, H., Zhang, M., Zhang, R., et al. (2021). Recent advances in cellulose and its derivatives for oilfield applications. Carbohydr. Polym. 259:117740. doi: 10.1016/j.carbpol.2021.117740

Liu, T., Greenslade, A., and Yang, S. C. (2017). Levels of rhizome endophytic fungi fluctuate in Paris polyphylla var. yunnanensis as plants age. Plant Diver. 39, 60-64. doi: 10.1016/j.pld.2016.11.006

Liu, W., Du, H., Liu, H., Xie, H., Xu, T., Zhao, X., et al. (2020a). Highly efficient and sustainable preparation of carboxylic and thermostable cellulose nanocrystals via FeCl3-catalyzed innocuous citric acid hydrolysis. ACS Sustain. Chem. Eng. 8, 16691-16700. doi: 10.1021/acssuschemeng.0c06561

Liu, W., Du, H., Liu, K., Liu, H., Xie, H., Si, C., et al. (2021). Sustainable preparation of cellulose nanofibrils via choline chloride-citric acid deep eutectic solvent pretreatment combined with high-pressure homogenization. Carbohydr. Polym. 267:118220. doi: 10.1016/j.carbpol.2021.118220

Liu, W., Du, H., Zhang, M., Liu, K., Liu, H., Xie, H., et al. (2020b). Bacterial cellulosebased composite scaffolds for biomedical applications: a review. ACS Sustain. Chem. Eng. 8, 7536-7562. doi: 10.1021/acssuschemeng.0c00125

Liu, X. D., Wang, Z. H., and Xu, Y. Q. (2015). Research progress of Chinese herbal medicine Paris. Guid. J. TCM 21, 90-93.

Ma, C., Ma, M. G., Si, C., Ji, X. X., and Wang, P. (2021a). Flexible mxene-based composites for wearable devices. Adv. Funct. Mater. 1:2009524. doi: 10.1002/ adfm. 202009524

Ma, C., Kim, T.-H., Liu, K., Ma, M.-G., Choi, S.-E., and Si, C. (2021b). Multifunctional lignin-based composite materials for emerging applications. Front. Bioeng. Biotechnol. 9:708976. doi: 10.3389/fbioe.2021.708976

Ma, C., Yuan, Q., Du, H., Ma, M. G., Si, C., and Wan, P. (2020). Multiresponsive MXene $\left(\mathrm{Ti}_{3} \mathrm{C}_{2} \mathrm{~T}_{x}\right)$-decorated textiles for wearable thermal management and human motion monitoring. ACS Appl. Mater. Interfaces 12, 34226-34234. doi: 10.1021/acsami.0c10750

National Pharmacopoeia Commission (2015). Pharmacopoeia of PR China, 2015 Edn, Vol. I. Beijing: China Pharmaceutical Science and Technology Press, 260.

Negi, J. S., Bisht, V. K., Bhandari, A. K., Bhatt, V. P., Singh, P., and Singh, N. (2014). Paris polyphylla: chemical and biological prospectives. Anti Cancer Agents Med. Chem. 14, 833-839. doi: 10.2174/1871520614666140611101040 
Ou, H., Guo, D. Q., Lin, J. J., Yan, Z. Y., Teng, Z., Wang, G. Z., et al. (2016). Effects of different AM fungi on quantity and enzyme activity of Hizosphere soil microorganism of Paris polyphylla var. Yunnanensis. J. Chin. Med. Mater. 39, 948-955.

Pei, Y. F., Zhang, Q. Z., and Wang, Y. Z. (2020). Application of authentication evaluation techniques of Ethnobotanical medicinal plant genus Paris: a review. Crit. Rev. Analyt. Chem. 50, 405-423. doi: 10.1080/10408347.2019.1642734

Qin, X. J., Sun, D. J., Ni, W., Chen, C. X., Hua, Y., He, L., et al. (2012). Steroidal saponins with antimicrobial activity from stems and leaves of Paris polyphylla var. yunnanensis. Steroids 77, 1242-1248. doi: 10.1016/j.steroids.2012. 07.007

Qin, X. J., Yu, M. Y., Ni, W., Yan, H., Chen, C. X., Cheng, Y. C., et al. (2016). Steroidal saponins from stems and leaves of Paris polyphylla var. yunnanensis. Phytochemistry 121, 20-29. doi: 10.1016/j.phytochem.2015.10.008

Shen, S., Xu, Z., Feng, S. L., Wang, H. D., Liu, J., Zhou, L. J., et al. (2018). Structural elucidation and antiaging activity of polysaccharide from Paris polyphylla leaves. Intern. J. Biol. Macromol. 107, 1613-1619. doi: 10.1016/j.ijbiomac.2017. 10.026

Shen, S. A., Chen, D. J., Li, X., Li, T., Yuan, M., Zhou, Y. H., et al. (2014). Optimization of extraction process and antioxidant activity of polysaccharides from leaves of Paris polyphylla. Carbohyd. Polym. 104, 80-86. doi: 10.1016/j. carbpol.2014.01.006

Si, C. L., Deng, X. J., Liu, Z., Kim, J. K., and Bae, Y. S. (2008a). Studies on the phenylethanoid glycosides with anti-complement activity from Paulownia tomentosa var. tomentosa wood. J. Asian Nat. Products Res. 10, 1003-1008.

Si, C. L., Liu, Z., Kim, J. K., and Bae, Y. S. (2008b). Structure elucidation of phenylethanoid glycosides from Paulownia tomentosa Steud. var. tomentosa wood. Holzforschung 62, 197-200. doi: 10.1515/hf.2008.047

Si, C. L., Jiang, J. Z., Liu, S. C., Hu, H. Y., Ren, X. D., Yu, G. J., et al. (2013). A new lignan glycoside and phenolics from the branch wood of Pinus banksiana Lambert. Holzforschung 67, 357-363. doi: 10.1515/hf-2012-0137

Si, C. L., Wu, L., and Zhu, Z. Y. (2009). Phenolic glycosides from Populus davidiana bark. Biochem. Syst. Ecol. 37, 221-224. doi: 10.1016/j.bse.2009.01.007

Song, Y., Li, M. F., and Xu, J. (2015). Polymorphic microsatellite markers in the traditional Chinese medicinal plant Paris polyphylla var. yunnanensis. Genet. Mol. Res. 14, 9939-9942. doi: 10.4238/2015.august.19.29

Vos, P., Hogers, R., Bleeker, M., Reijans, M., van de Lee, T., Hornes, M., et al. (1995). AFLP: a new technique for DNA fingerprinting. Nucleic Acids Res. 23, 4407-4414.

Wang, G. X., Han, J., Zhao, L. W., Jiang, D. X., Liu, Y. T., and Liu, X. L. (2010). Anthelmintic activity of steroidal saponins from Paris polyphylla. Phytomedicine 17, 1102-1105. doi: 10.1016/j.phymed.2010.04.012

Wang, H., Du, H., Liu, K., Liu, H., Xu, T., Zhang, S., et al. (2021). Sustainable preparation of bifunctional cellulose nanocrystals via mixed $\mathrm{H}_{2} \mathrm{SO}_{4}$ /formic acid hydrolysis. Carbohydr. Polym. 266:118107. doi: 10.1016/j.carbpol.2021.118107

Wang, H., Xie, H., Du, H., Wang, X., Liu, W., Duan, Y., et al. (2020). Highly efficient preparation of functional and thermostable cellulose nanocrystals via $\mathrm{H}_{2} \mathrm{SO}_{4}$ intensified acetic acid hydrolysis. Carbohydr. Polym. 239:116233. doi: 10.1016/j.carbpol.2020.116233

Wang, Q., Yang, M., Guo, D. Q., Tang, D. H., Mu, M. J., Huang, Y., et al. (2019). Determination of monosaccharide composition of polysaccharides from wild and transplanted Paris polyphylla var. yunnanensis by HPLC with PMP pre-column derivatization. Chin. Drug Res. Clin. Pharmacol. 30, 1503-1509.

Wang, Q., Zhang, H. J., Yang, M., Zhang, H., Zhou, N., and Li, Y. (2018). Effects of 28 species of AM fungi on diosgenin contents in Paris polyphylla var. yunnanensis. J. Dali Univer. 3, 22-25.

Wang, Y., Wang, H. P., Cheng, H. Y., Chang, F., Wan, Y., and She, X. P. (2020). Niche differentiation in the Rhizosphere and Endosphere fungal microbiome of wild Paris polyphylla Sm. Peerj 8:e8510. doi: 10.7717/peerj.8510

Wu, X., Wang, L., Wang, H., Dai, Y., Ye, W. C., and Li, Y. L. (2012). Steroidal saponins from Paris polyphylla var. yunnanensis. Phytochemistry 81, 133-143. doi: 10.1016/j.phytochem.2012.05.034

Xu, J., Li, C., Dai, L., Xu, C., Zhong, Y., Yu, F., et al. (2020). Biomass fractionation and lignin fractionation towards lignin valorization. ChemSusChem 13, 42844295. doi: $10.1002 /$ cssc. 202001491

Xu, J., Shao, Z., Li, Y., Dai, L., Wang, Z., and Si, C. (2021). A flow-through reactor for fast fractionation and production of structure-preserved lignin. Ind. Crops Prod. 164:113350. doi: 10.1016/j.indcrop.2021.113350
Xu, R., Du, H., Liu, C., Liu, H., Wu, M., Zhang, X., et al. (2021). An efficient and magnetic adsorbent prepared in a dry process with enzymatic hydrolysis residues for wastewater treatment. J. Clean. Prod. 313:127834. doi: 10.1016/j. jclepro.2021.127834

Xuan, Q., Bao, F. K., Pan, H. M., and Liu, A. H. (2010). Isolating fungal endophyte from Paris polyphylla Smith var. yunnanensis and identifying their antibacterial ability. Afri. J. Microbiol. Res. 4, 1001-1004.

Yan, L. L., Zhang, Y. J., Gao, W. Y., Man, S. L., and Wang, Y. (2009). In vitro and in vivo anticancer activity of steroid saponins of Paris polyphylla var. yunnanensis. Exper. Oncol. 31, 27-32.

Yang, L. L., Tang, S. K., Chu, X., Jiang, Z., Xu, L. H., and Zhi, X. Y. (2016). Oceanobacillus endoradicis sp nov., an endophytic bacterial species isolated from the root of Paris polyphylla Smith var. yunnanensis. Antonie Van Leeuwenhoek Intern. J. Gen. Mol. Microbiol. 109, 957-964. doi: 10.1007/s10482016-0695-4

Yang, M., Guo, D. Q., Shen, Y. X., Pan, X. J., Zhang, J., Zhang, J., et al. (2017). Optimization of extraction of nucleosides from Paris polyphylla var. yunnanensis by orthogonal test. J. S. Agric. 48, 876-882.

Yang, M., Wang, R., Zhou, N., Tang, S. F., and Shen, Y. X. (2018). Analysis of 14 elements in Paris polyphylla in Yunnan and Guizhou. Heilongjiang Anim. Sci. Vet. Med. 8, 200-205.

Yang, X., Xie, H., Du, H., Zhang, X., Zou, Z., Zou, Y., et al. (2019). Facile extraction of thermally stable and dispersible cellulose nanocrystals with high yield via a green and recyclable $\mathrm{FeCl}_{3}$-catalyzed deep eutectic solvent system. ACS Sustain. Chem. Eng. 7, 7200-7208. doi: 10.1021/acssuschemeng.9b00209

Yang, X., Xie, H., Zou, Y., Huang, Y., Jiang, L.-W., Wang, X., et al., (2021). Cost-effective and efficient plum-pudding-like $\mathrm{Fe}_{\mathrm{X}} \mathrm{Ni}_{1-\mathrm{X}} \mathrm{S}_{2} / \mathrm{C}$ composite electrocatalysts for oxygen evolution reaction. Renew. Energ. 168:416e423. doi: 10.1016/j.renene.2020.12.072

Yang, Y., Yang, S. C., Zhao, J., Udikeri, S., and Liu, T. (2015). Microbial diversity in Paris polyphylla var. yunnanensis rhizomes of varying ages. Genet. Mol. Res. 14, 17612-17621. doi: 10.4238/2015.december.21.34

Zhang, H., Du, H. H., Guo, D. Q., Yang, M., Wang, M. J., and Zhou, N. (2019). Effects of inoculation with different AM fungi on functional gene expression in seedlings of Paris polyphylla var. Yunnanensis. Nat. Product Res. Dev. 31, 318-324.

Zhang, J., Ding, B., Zhang, H., Qi, J. S., Shen, Y. X., Zhou, N., et al. (2016). Effects of different drying methods on total saponin content and antioxidant capacity of Paris polyphylla var. Yunnanensis. Chin. J. Inform. Trad. Chin. Med. 23, 95-97.

Zhang, J. Y., Yu, H., and Zhang, S. G. (2004). RAPD analysis of genetic diversity of Paris polyphylla. Biodiversity 12, 517-522.

Zhang, Y., Lü, S. S., Zhou, N., Ma, Y. X., Gao, K. J., and Wu, S. W. (2011). Comparison of 4 kinds of chonglou saponins contents in Paris polyphylla of different growing years. China Pharm. 22, 4081-4083.

Zhao, J. J., Huang, Y., Zhang, D. Q., and Zhou, N. (2020). Phylogeography of Paris poliphylla var. yunnanensis based on chloroplast gene trnL-trnF sequences. China J. Chin. Mater. Med. 46, 1094-1101.

Zhao, X. P., Zou, G. F., Zhao, J., Hu, L. Y., Lan, Y. F., and He, J. L. (2020). Genetic relationships and diversity among populations of Paris polyphylla assessed using SCoT and SRAP markers. Physiol. Mol. Biol. Plants 26, 1281-1293. doi: 10. 1007/s12298-020-00808-Z

Zhao, Y., Kang, L. P., Liu, Y. X., Liang, Y. G., Tan, D. W., Yu, Z. Y., et al. (2009). Steroidal saponins from the rhizome of Paris polyphylla and their cytotoxic activities. Planta Med. 75, 356-363. doi: 10.1055/s-0028-1088380

Zhou, L. A., Yang, C. Z., Li, J. Q., Wang, S. L., and Wu, J. Y. (2003). Heptasaccharide and octasaccharide isolated from Paris polyphylla var. yunnanensis and their plant growth-regulatory activity. Plant Sci. 165, 571-575. doi: 10.1016/s01689452(03)00216-4

Zhou, L. G., Cao, X. D., Yang, C. Z., Wu, X. H., and Zhang, L. Q. (2004). Endophytic fungi of Paris polyphylla var. yunnanensis and analysis of their steroids. Nat. Product Res. Dev. 16, 120-198.

Zhou, N., Ding, B., Feng, Y., Qi, W. H., Zhang, H., Guo, D. Q., et al. (2015a). Effects of mycorrhizal colonization and medicine quality of Paris polyphylla var. yunnanensis inoculated by different foreign AM fungi species. China J. Chin. Mater. Med. 40, 3158-3167.

Zhou, N., Zhang, H. Q., Ding, B., Guo, D. Q., Zhang, D. Q., Zeng, Y., et al. (2015b). Effects of different drying methods on the content of diosgenin 
in Paris polyphylla var. yunnanensis. Lishizhen Med. Mater. Med. Res. 26, 361-362.

Zhou, N., Guo, D. Q., Wang, K. T., Zhang, D. Q., Peng, G. H., and Zhang, C. Q. (2014). Comparative study on different extraction methods of polysaccharide from Paris polyphylla var.yunnanensis. Sci. Technol. Food Industry 35, 326-329.

Zhou, N., Guo, J. F., Yang, L. Y., Xu, P., and Jiang, B. (2010). Determination of diosgenin in Paris polyphylla var. yunnanensis at different collecting time by HPLC. Chin. J. Exper. Trad. Med. Formul. 16, 54-56.

Zhou, N., Zhang, D. Q., Sun, Q., Jiang, B., and Huang, Z. C. (2012). Effects of fungal elicitors on the secondary metabolite steroidal saponin in Paris polyphylla var. yunnanensis. Acta Pharm. Sinica 47, 1237-1242.

Zhou, N., Zhang, J., Pan, X. J., Du, H. H., Guo, D. Q., Ding, B., et al. (2017). Effect of arbuscular mycorrhizal fungi on endogenous hormones in Paris polyphylla var. Yunnanensis. Chin. Trad. Herb. Drugs 48, 4970-4978.
Zhou, Y., Yang, M., Guo, D. Q., Pan, X. J., Ding, B., Zhang, J., et al. (2020). Effects on the Rhizosphere soil environment and the medicine quality of Paris polyphylla var. yunnanensis inoculated by different exogenous AM fungi combination. Chin. J. Exper. Trad. Med. Formul. 26, 96-109.

Conflict of Interest: The authors declare that the research was conducted in the absence of any commercial or financial relationships that could be construed as a potential conflict of interest.

Copyright (C) 2021 Zhou, Xu, Park, Ma, Choi and Si. This is an open-access article distributed under the terms of the Creative Commons Attribution License (CC BY). The use, distribution or reproduction in other forums is permitted, provided the original author(s) and the copyright owner(s) are credited and that the original publication in this journal is cited, in accordance with accepted academic practice. No use, distribution or reproduction is permitted which does not comply with these terms. 